\title{
Exploring the similarities and differences in the forgiveness of the elders living in the old-age homes and the families
}

\author{
Charu Prabhakar ${ }^{1}$, Love Kumar Mishra ${ }^{2}$, Poonam Sharma ${ }^{3}$, Gyanesh Kumar Tiwari ${ }^{4}$, \\ Rakesh Pandey ${ }^{5}$, Meenakshi Shukla ${ }^{6}$, Akash Bajpai ${ }^{7}$, and Pramod Kumar Rai ${ }^{8}$ \\ ${ }^{1}$ Masters Student, Department of Psychology, School of Humanities \& Social Sciences, \\ Doctor Harisingh Gour Vishwavidyalaya, Sagar, 470003, Madhya Pradesh, India, Email: \\ charu26@icloud.com \\ ${ }^{2}$ Masters Student, Department of Psychology, School of Humanities \& Social Sciences, \\ Doctor Harisingh Gour Vishwavidyalaya, Sagar, 470003, Madhya Pradesh, India, Email: \\ love1996love92@gmail.com \\ ${ }^{3}$ Masters Student, Department of Psychology, School of Humanities \& Social Sciences, \\ Doctor Harisingh Gour Vishwavidyalaya, Sagar, 470003, Madhya Pradesh, India, Email: \\ poonamps1295@gmail.com \\ ${ }^{4}$ Assistant Professor, Department of Psychology, School of Humanities \& Social Sciences, \\ Doctor Harisingh Gour Vishwavidyalaya, Sagar, 470003, Madhya Pradesh, India, Email: \\ gyaneshpsychology@gmail.com \\ ${ }^{5}$ Professor, Department of Psychology, Faculty of Social Sciences, Banaras Hindu \\ University, Varanasi, 221005, Uttar Pradesh, India, Email: rpandeybhu@gmail.com \\ ${ }^{6}$ Assistant Professor, Department of Psychology, Magadh University, Bodh Gaya, 824234, \\ Bihar, India. Email: meenakshis hukla@hotmail.com \\ ${ }^{7}$ Masters Student, Department of Psychology, School of Humanities \& Social Sciences, \\ Doctor Harisingh Gour Vishwavidyalaya, Sagar, 470003, Madhya Pradesh, India, Email: \\ akash.bajpai78@gmail.com \\ ${ }^{8}$ Professor, Department of Psychology, School of Humanities \& Social Sciences, Doctor \\ Harisingh Gour Vishwavidyalaya, Sagar, 470003, Madhya Pradesh, India, Email: \\ prof.pkrai@gmail.com
}

August 5, 2020

\begin{abstract}
Objectives: Researchers have reported close links between forgiveness and positive life outcomes for people of all age groups. The study explored the perceived transgressions and forgiveness of the elders using a qualitative research design.

Design and Methods: Narrative qualitative research design was employed. The semi-structured interview was used to collect data of 10 elders of old-age homes (Mean age $=67.20, \mathrm{SD}=4.57)$ and 12 elders residing with their families $($ Mean age $=69.33$, $\mathrm{SD}=4.21)$ which were analysed through thematic analysis.

Results: Severe loss, serious neglect and cheating were the major perceived transgressions of the old-age home elders whereas day-to-day issues characterized the perceived transgressions of the family elders. Pseudo-forgiveness was observed in the elders of old-age home because of helplessness and their fear of losing respect while affiliation, perceived harm, the realisation of offence, and perceived consequences of punishment were precursors for the forgiveness in family-living elders. Both the groups acknowledged the role of offence, intention, relationships, attributions and commitment to socio-cultural and moral values in forgiveness.
\end{abstract}


Implications: The differences in the perceived transgressions, poor social support and negative cognitions were significant factors behind the dissimilar forgiveness of the two groups. Cultural conceptualizations of relationships, morality, emotion regulation, health issues, spiritual beliefs and interpersonal resources seem to regulate the forgiveness of the elders. Heterogeneity Hypothesis, implicit theories of relationship, just world belief and stress-buffering theory were used to explain the findings. Practitioners may use forgiveness interventions to improve positive life outcomes of the elders. Practitioners may consider providing social support and reducing negative cognitions to facilitate elders' forgiveness.

Keywords: forgiveness, elders, old-age home, transgressions, thematic analysis.

\section{Introduction}

Forgiveness refers to the willingness to give up resentment, grudges and negative feeling towards self, other persons, groups and communities in the face of perceived wrongdoings on one hand and fostering compassion, generosity and love toward these stakeholders on the other (Enright et al., 1998). Forgiveness represents a significant construct in understanding a variety of positive life outcomes of individuals, groups, organizations and other collectives (Lee \& Enright, 2019; Stone, 2002; Webb \& Toussaint, 2020). Forgiveness has been found to be efficacious for internal harmony, positive emotional and cognitive consequences, reparative contributions, compassion and understanding, well-being, health and other life outcomes, productive relationships and focus on the present (Davis et al., 2015; Lee \& Enright, 2019; R. Pandey, Tiwari, Pandey, et al., 2020; R. Pandey, Tiwari, Parihar, et al., 2020). Forgiveness has been suggested to carry positive emotions that directly strengthen physical and psychological health by shaping perceptions, attributions and physiological processes of people (D. E. Davis et al., 2015; Webb \& Toussaint, 2020). Moreover, forgiveness has been reported to lower psychopathological symptoms in College students and adults (Nsamenang et al., 2013) and even relevant to understand life outcomes of children (Ahirwar et al., 2019). The positive impacts of forgiveness have been explained in terms of its protective and strengthening attributes that entail reparation, resilience, coping and enhanced self-acceptance (McCullough, 2008; Toussaint et al., 2020).

The number of older people is escalating due to increased medical and old-age home facilities, and new government policies across the globe (The United Nations, 2019). The United Nations (2019) has set the goal to ensure healthy lives and promote well-being for all. It has been suggested that healthy ageing could be achieved through proper interventions to modify the underlying physiological and psychological changes associated with ageing (World Health Organization, 2019). A good number of older people have been compelled to live in old-age homes as a result of worldwide changes in the family structures, shifts in roles and social positions, increasing cost of living, generation gap and adoption of postmodern lifestyles (World Health Organization, 2019). This necessitates the understanding of the needs of older adults in maintaining their health and well-being (World Health Organization, 2019).

It is explicit from the above discussion that forgiveness is efficacious in understanding a variety of life outcomes of individuals of different age groups. Studies on forgiveness show that among other factors, forgiveness is associated with age, such that older people are more forgiving than younger ones (Toussaint et al., 2001). Forgiveness has been suggested to play a significant role in successful ageing (Hantman \& Cohen, 2010). It has been argued that older people are more forgiving because they are more religious (Lawler-Row, 2010) and ruminate less (Ingersoll-Dayton et al., 2010). Some personality attributes such as agreeableness and neuroticism may change with the increasing age which has been associated with the forgiveness of older adults (Steiner et al., 2012). Since older people are aware that for them the end of life is near, they strive to find personal meaning in relationships and attain closure in order to achieve ego-integrity (Erikson \& Erikson, 1997), and one way to achieve this integrity is through forgiveness (Hantman \& Cohen, 2010). However, the benefits of forgiveness have been assessed more frequently for young adults in terms of interpersonal forgiveness and forgiveness in older adults have been less covered by previous studies despite the fact that same benefits like young adults may be expected for them also (Hayward \& Krause, 2013). 
It is noticeable that the forgiveness of older adults has not been properly studied and most of them have employed quantitative methods and Western samples (Akhtar et al., 2017; Toussaint \& Webb, 2005). Thus, there is significant lack of qualitative studies of the elders' forgiveness (Dorn et al., 2014; Maynard et al., 2016; Webb \& Toussaint, 2020) that has resulted in the lack of proper and in-depth understanding of the culture-embedded mechanisms of forgiveness through which it may impact life outcomes of older adults (Hayward \& Krause, 2013). The understanding of forgiveness has many practical implications and may be relevant for health professionals, researchers and policymakers to improve public health (Akhtar et al., 2017). Use of qualitative methods has been suggested to be the most appropriate when the researchers intend to develop an understanding of the nature and attributes of complex constructs like forgiveness, there is no guiding framework, or if a phenomenon is to be explored in-depth (Creswell et al., 2004). Additionally, the nature and extent of forgiveness may differ in older individuals as their life challenges significantly differ from those of adults. For instance, older adults may face stressful and negative life experiences a result of institutionalization that may impact their perception of transgressions and pose challenges before their forgiveness (Guarnaccia \& Zautra, 1996). However, hardly any study has explored how the nature and dynamics of perceived transgression and forgiveness may differ between older adults staying in old-age homes and those who live with their families. Since community ties and pro-sociality have weakened in recent times due to changes in social and family structures (Bellah et al., 2008; Putnam, 2007), the number of old age people residing in old-age homes in India and rest of the world is increasing at a fast pace (Menezes \& Thomas, 2018).

Since older individuals residing in old-age homes are more vulnerable to mental health problems of depression and anxiety (N. M. Pandey et al., 2012), it becomes important to explore the nature and sources of perceived transgressions and processes of forgiveness among elders residing in old-age homes compared to those residing with families to tap its strengthening and protective strengths to improve their health and well-being (Griffin et al., 2020; Toussaint et al., 2020; Webb \& Toussaint, 2020). In this backdrop, the present study was designed to understand the nature and dynamics of the perceived transgressions and dynamics of forgiveness of older adults residing in old-age homes and with their families employing a qualitative research design.

\section{Research Design and Methods}

\section{Participants}

Ten older adults, 6 males in the age range of $61-76$ years $(\mathrm{M}=66.17$ years, $\mathrm{SD}=5.19)$ and 4 females in the age range of $65-73$ years $(\mathrm{M}=68.75, \mathrm{SD}=3.50)$ were chosen from old-age homes [BLINDED FOR REVIEW] in India. Twelve elders participants residing with their families, comprising 6 males in the age range of $65-76$ years $(\mathrm{M}=69.83, \mathrm{SD}=4.36)$ and 6 females aged $64-75$ years $(\mathrm{M}=68.83, \mathrm{SD}=4.40)$ were chosen as the comparison group. There was no significant difference in the mean ages of older people living in old-age homes $(\mathrm{M}=67.20, \mathrm{SD}=4.57)$ and those living in their families $(\mathrm{M}=69.33, \mathrm{SD}=4.21)$, $(\mathrm{t}(20)=1.14, p=.268)$. The inclusion criteria for the participants were an age of 60 years or above and no apparent disability or health issues of any kind. Additionally, only such old-age home participants were chosen who had been living in the old-age homes for at least 5 years so that they have sufficient experience of the living there (see detailed demographics in Table 1 and Table 2). The steps of sample extraction are presented in Appendix 1 and Appendix 2.

Table 1. Demographic details of the elder adults living in the old-age homes $(N=10)$

\section{Demographic Features}

\section{Frequency}




\section{Percentage}

Age (Years)

61-65

05

$50 \%$

66-70

03

$30 \%$

71-75

01

$10 \%$

76- 80

01

$10 \%$

\section{Gender}

Male

06

$60 \%$

Female

04

$40 \%$

Religion 
Hindu

10

$100 \%$

Domicile

Rural
08
$80 \%$
Urban
02
$20 \%$

Marital Status

\section{Married}

02

$20 \%$

Widow

03

$30 \%$

Widower

05 
$50 \%$

Educational Levels

\author{
Illiterate \\ 05 \\ $50 \%$ \\ V Standard \\ 01 \\ $10 \%$ \\ VIII Standard \\ 02 \\ $20 \%$ \\ X Standard \\ 02 \\ $20 \%$
}

Table 2. Demographic details of the older adults living with their families $(\mathrm{N}=12)$

Demographic Features

\author{
Frequency \\ Percentage \\ Age (Years) \\ $61-65$
}


04

$33.33 \%$

66-70

03

$25.00 \%$

71-75

04

$33.33 \%$

76-80

01

$8.34 \%$

Gender

Male

06

$50 \%$

Female

06

$50 \%$

Religion

Hindu

10

$100 \%$ 


\title{
Domicile
}

\author{
Rural \\ 04 \\ $33.33 \%$ \\ Urban \\ 08 \\ $66.33 \%$
}

Marital Status

Married

09

$75.00 \%$

Widow

02

$16.67 \%$

Widower

01

$8.34 \%$

Educational Levels

Illiterate 
V Standard

02

$16.67 \%$

VIII Standard

03

$25.00 \%$

X Standard

03

$25.00 \%$

\section{Data Saturation}

The saturation was indicated when no new themes and codes emerged from additional interviews consistent with the research questions (Saunders et al., 2018). The inductive thematic saturation was adopted that focuses on the identification and number of new codes and themes. The inductive thematic saturation occurred with the completion of 8 and 10 interviews of the elders of the old-age homes and the families, respectively but an additional two interviews from each group were taken to confirm the saturation.

\section{Materials}

The data of the study were collected through a pre-developed semi-structured interview protocol. The researchers were free to add some pertinent queries in the interview protocol based on their insights and understanding with the progression of data collection, regular consultations and new findings and discussions among the authors. The interviews of the participants were audio-recorded and transcribed verbatim by the first three and last authors using a mobile phone recorder. The insights of the pilot study led to the finalisation of the questions for the interview.

\section{Procedure}

\section{Initial development of Interview protocol}

The research proposal was submitted to the Ethics Committee of the University [BLINDED FOR REVIEW]. Before the start of actual data collection, some consensus meetings and pilot interviews were carried out employing two males (average age $70 \pm 2.83$ years) and two females (average age $68.50 \pm 3.54$ years) to develop a preliminary interview protocol. The data of these participants were not included in the final analysis. This step also helped to understand that the participants may be able to talk about their experiences of transgressions and forgiveness in their life. 


\section{Interview Process}

According to the protocol, in-depth interviews were carried out in Hindi or Bundelkhandi, audiotaped and verbatim transcriptions were prepared according to the guidelines of leading researchers (Byrne, 2016; Howitt, 2016). The average duration of the interviews was 56.34 minutes. Some initial questions were asked at the beginning that followed focused questions regarding the nature, severity and sources of transgressions and processes, strategies and consequences of forgiveness of the elders. The codes were allotted, verbatim transcriptions were prepared and their accuracy, completeness and consistency were ascertained along with the conduct of each interview (Howitt, 2016). The care was taken to minimize the incongruity in power and emotional labour demands between the interviewers and the participants by recognizing that the participants were the only and significant sources to learn about the transgressions and forgiveness for the interviewers (Hoffmann, 2007). The interviews were organized at the residence for the ease and convenience of the participants. The participants were assured about their privacy and confidentiality.

\section{Data Analysis}

The transcriptions of the interviews were read multiple times to enhance the familiarity with the data and develop an in-depth understanding of the contents to assign appropriate codes. The contents of the interviews were coded by the first three and last authors adopting the following criteria: nature, severity and sources of perceived transgressions, and need, challenges and significance of forgiveness. Following the guidelines of Barbour (2001), the interview contents were coded and reviewed for multiple times to resolve inconsistencies and to increase reliability. Initially, four transcripts were assessed for the suitability of the criteria of generating codes mentioned above by the authors (fourth, fifth, sixth and seventh) to assess the suitability of the criteria and richness of the transcriptions independently followed by a meeting to finalize the coding framework.

The coding framework was regularly assessed and reviewed by all the authors to incorporate relevant modifications to identify the codes. Further refining of the coding process was done to assess the usefulness, appropriateness, effectiveness and suitability through team discussions that helped to reorganize, merge and re-categorize codes leading to emerge more useful codes and drop irrelevant codes (Guest et al., 2012). An iterative approach was adopted to check the loss of the missing relevant codes and capture pertinent data that involved the review and inclusion of useful codes in previous transcriptions. After completion of the interviews were, each transcript was scrutinized for coding check that involved reviewing the initial codes after a reasonable gap with a fresh look to lower the danger of distortions due to over-involvement in the data (Guest et al., 2012). The contents, the emerged descriptions and the codes of the interviews were studied and explored by using inductive and deductive thematic analysis method (Braun \& Clarke, 2006) and constructionist approach that facilitated the emergence of initially less structured narratives to more structured facts in accordance with the research questions.

\section{Results}

\section{Perceived transgressions and forgiveness of the elders of the old-age homes}

Three major themes emerged regarding the nature of perceived transgressions and mechanisms of forgiveness of the elders of old-age home. Theme 1 showed that forgiveness revolved around the loss of close relatives or unbearable cheating. The loss of close relative left a stable mark on the very meaning of life and will to live of the older adults. One old-aged male (M_1) participant expressed his views: "[..... My son was murdered [.....] that was the body of my son and the murderers were of Balakot [.....]. We became helpless as our daughter-in-law didn't understand [......." In other cases, cheating, lack of care and support, extreme insult and neglect on the part of family members and other relatives were observed that distorted the perceptions and social behaviour of the elders. A male elder participant (M_4) said: "[.....] One stole my 2 crore rupees. If he needed it he should have asked for it. [.....] They illegally captured my father's home 
which is not of 10,000 rupees or so but has value in crores [.....]." Quarrelsome and hurtful behaviours of family members were other causes of negative perceptions of majority of the old-age home elders.

Theme 2 denoted that many negative psychological attributes get appended in the cognitive, affective and behavioural response repertoire of the elders. Negative attribution style and cognitions were the reasons behind the poor forgiveness of the elders. For example, one male (M 6) expressed his hopelessness: "[..... They dragged him in a car, as they were about to beat him, I moved towards them and they pointed a gun on me [.....]. It was due to poor policing system." Perceived lack of social support, physical disabilities, egoistic and rigid nature were evident in the statements of old-age elders.

Guilt and frequent negative emotional experiences, inability to express their emotions, anguish and strong compensatory desires dominated the affective responses resulting in low forgiveness of the elders. Guilt was very common in their expressions. Many maladaptive patterns were linked with the non-forgiving behaviours of the elders. For instance, one male (M_1) said: "[.....] Son and daughter-in-law both came and requested to return home but I refused [.....]. I won't go back as she used to throw the plate in such a disgusting way that the food used to come on my face [.....]." Non-acceptance of decisions, poor social skills, withdrawal and pseudo-forgiveness were commonly observed in the behaviours of these elders. It may be due to their negative feelings and poor health conditions.

Theme 3 indicated that forgiveness was closely linked with the social pressure and expectations, prevalent moral values and fear of defamation. Fear of losing respect and defamation compelled the elders to show pseudo-forgiveness. One elder male (M_5) reported fear of losing respect and apprehension of loss of regard in these words: "[.....] Whenever he came back home [.....]. I couldn't punish him by beating him up as otherwise you people would be the one saying that the grandfather is so cruel that he is beating his married son, and if he had beaten me in return or said something then my respect would be lost [.....]." Prevalent moral and relational stereotypes and defamation were strong forces behind their pseudo-forgiveness.

Common humanistic and social values lowered the pain associated with current well-being and interpretations of the elders. For example, one male (M_4) expressed: "[..... We didn't want to attend the marriage of our grand-daughter but had to because of social obligation to do so [......"." Moreover, religious and spiritual values were another precursor behind their forgiveness. Poor health conditions and age-related disabilities played a significant role in the forgiveness of the majority of old-age home elders. The detailed themes and their descriptions have been presented in Appendix 3.

\section{Perceived transgressions and forgiveness of the elders living with their families}

Theme 1 showed that the elders exhibited apprehension in expressing transgressions for fear of conflict with their family members. Majority of the elders living with their families did not find it easy to express themselves due to apprehension of defamation, conflicts, or insecurity and fear of losing respect from family members. For example, one male participant (M-1) said: "/.... I I don't talk irrelevantly with them because I fear that they might taunt or say something that might hurt me in return, so I stay calm. Yes, she asks for forgiveness. Despite feeling angry I forgive her. I do not talk much. I mind my own business. I go, have food and then come back [.....]."

Theme 2 indicated that the elders emphasized a small scolding/punishment as important for forgiveness. These elders believed that forgiveness may be facilitated by giving small punishment, rebukes and interaction with transgressor/s (making the transgressor/s understand). One female (F-1) said: "/..... No, I forgive. She knows how to do the work as she is handling and managing the whole house, so, knows it better. See if it is a family issue then we can scold or punish by slapping but we can't beat any outsider [.....]." The role of small rebuke, reprimand and scolding in forgiveness was surfaced in the verbalizations of the majority of the elders living in their family.

Theme 3 denoted that forgiveness of the elders was significantly shaped by their belongingness 
and good relationship with their family members. Dependency and need for affiliation may be the major forces behind the forgiveness of elders living with their families. For example, one male participant (M-3) said: "[.....] As I told, whenever tea comes I have tea, when a meal comes I have it [.....]. There is no need for any word. My bed is sufficient for me. What is forgiving others' mistake? Whatever happened is fine [....] will make him/her understand and will not consult him/her after that; others' mistake has no meaning. But if the same mistake is done by some family member, then it needs to be definitely adjusted and resolved immediately. If the mistake is done by one among the four brothers of a family then remaining three will make him understand that it is his mistake [.....]."

Theme 4 indicated that isolation, withdrawal, and guilt played a more implicit role in the forgiveness of the elders. Hidden isolation and withdrawal regulated the nature of and extent of transgressions and forgiveness in the elders living with their families. For example, one male (M-6) said: "/..... I will tell you one thing that it's good if you try to mix up with me, live appropriately and happily with me and if in case I learned that you are having issues with me then I would automatically stop talking with you [.....] Now neither I have any concern for her nor does she have [.....] I don't talk about anything else as there is no need of it; it's just me and my bed. I do not talk much [....... I mind my own business. It's just that I go and have meals and return [......." The detailed themes and their descriptions have been presented in Appendix 4.

\section{Common Themes of Forgiveness}

Theme 1 showed that forgiveness signified a complex process that involved psychological, sociocultural and situational factors. Forgiveness of the elders involved complex attributions. For example, one male (M_2) said: "[.....] Everything has a limit. Actually, what happens is that if you try to change or mould a person, he/she will change to a certain extent and after that, the person will rebel. So, you shouldn't put so many restrictions on somebody that the other person is compelled to lose his/her patience." Forgiveness was closely associated with the socio-cultural and moral values of the elders.

Theme 2 indicated that the nature and types of transgression were important for forgiveness. For example, a male (M-6) participant said: "[..... If the mistake is small then it can be ignored. Just by getting angry on the wrongdoer and making him understand that you have to change and shouldn't repeat the mistake will be good for both of us. [......." Reparability of harm is also an important ingredient of forgiveness. Moral violations involved in the transgressions determined the degree of forgiveness of the elders.

Theme 3 denoted that relationship with and the perceived role of transgressor played a valuable role in forgiveness in the elders. Relationship with the transgressor was an important catalyst influencing forgiveness in the elders. A male participant (M-5) expressed his concern: "[..... What will you do if any family member does something wrong? We have to manage it and adjust with it [.....]." Acceptance of transgression prompted forgiveness in the elders. The age and gender of the transgressor shaped forgiveness in the elders.

The intention of committing wrongdoings was important for forgiveness in the elders. The nature of loss played an important role in forgiveness in the elders. Degree of reparability of harm may moderate forgiveness. One male ( $\left.\mathrm{M}_{-} 2\right)$ verbalised: "[.....] When the limit is crossed then there is no forgiveness. Everything has a limit and when this limit is crossed then there is no forgiveness no matter whether the wrongdoer is any family member or any outsider [......"'The detailed themes and their descriptions have been presented in Appendix 5.

\section{Discussion}

The study aimed at exploring the nature and consequences of perceived transgressions and dynamics of forgiveness of the elders of the old-age homes and the families. As per the Heterogeneity Hypothesis (Nelson 
\& Dannefer, 1992), there is a tendency for greater heterogeneity or difference among aged people since varied experiences accumulated over their life span differentiate one individual from the other. This difference is seen across a wide range of variables such as self-esteem and personal control (Nelson \& Dannefer, 1992), and it was suggested that the elders would show heterogeneity/differences in terms of their forgiveness as well, depending on whether they lived in an old-age home or with their families. Findings of this qualitative study revealed certain commonalities as well as distinctions across the two groups. It was observed that certain socio-cultural, humanistic and moral values influenced the forgiveness in both, the elders living in families and those living in old-age homes. Common humanity (Enright, 1996; Worthington et al., 2005) and morality (Satne, 2016) have been linked with forgiveness in previous literature.

Many significant findings surfaced about the perceived transgressions and forgiveness of the elders of the old-age homes. Theme 1 denoted that forgiveness revolved around the loss of close relatives or unbearable cheating. These negative experiences may be assumed to lower forgiveness in the elders of the old-age homes. About similar explanations have been proposed by some earlier researchers who suggested negative beliefs to play a negative role in forgiveness (Raj \& Wiltermuth, 2016). Besides, the elders of the old-age homes may perceive low social support due to constant neglect, loss, insult and hurtful behaviours by family members that might be working behind their low or pseudo-forgiveness. Thus, the poor forgiveness of the old-age home elders as compared to the family elders may be explained in terms of the stress-buffering theory that holds that poor social support (friends or family members) lowers emotional health and coping abilities (Cohen \& Wills, 1985) that in turn, may decrease their forgiveness (Maynard et al., 2016).

Theme 2 indicated that many negative psychological attributes get appended in the cognitive, affective and behavioural response repertoire of the old-age home elders. The findings showed that negative attributions and cognitions, perceived lack of social support, disabilities and inability to express their emotions, strong compensatory desires and withdrawal may have resulted in pseudo-forgiveness in the old-age home elders. Severe nature of perceived transgressions and poor social support may naturally result in more frequent negative emotional experiences and non-acceptance and poor social behaviours which in turn, may culminate in lower forgiveness (Cohen \& Wills, 1985; Maynard et al., 2016). Likewise, previous studies have argued that negative attributions (blame, intentionality) may lead to poor forgiveness (Davis \& Gold, 2011; Hall \& Fincham, 2006). These negative attributions may also result in avoidance, withdrawal and rigidity in one's behaviours that may be negatively related to forgiveness (Lichtenfeld et al., 2019).

Forgiveness observed in old-age home elders may be due to societal and moral pressures that were reflected in theme 3 that suggested forgiveness to be linked with the social pressure and expectations, prevalent moral values and fear of defamation. Thus, fear of losing respect, prevalent moral and relational stereotypes, fear of defamation, lowered common humanistic values, religious values, poor health conditions and age-related disabilities may be associated with forgiveness of old-age home elders. These jointly may have lowered Just World beliefs for self (JWB-S) that may be argued to decrease the forgiveness in oldage home elders. It has been suggested that JWB-S regulates the confidence in the predictability of events and outcomes of life and inbreed a sense of control and acts as a buffer against odds of life and impacts approach-oriented inclinations such as forgiveness (Bartholomaeus \& Strelan, 2016) via implicit theories of relationships that has been suggested to mediate the relation between Just World Beliefs and forgiveness (Knee et al., 2003). These facts inherent in the various themes may be said to denote poor JWB-S that may be argued to correlate negatively with the forgiveness of old-age home elders. The lowered common humanistic values, moral and relational stereotypes reported by the participants in this study, may be due to their lowered faith in JWB-S that may have posed challenges before their forgiveness (Bartholomaeus \& Strelan, 2016). Social pressure and expectations (Siassi, 2007) and social instances (McCullough, 2008) have been reported to be relevant to understanding forgiveness. It has been argued that higher familial and social values and commitments are significant for human beings despite wrongdoings, in facilitating forgiveness (Głaz, 2019; Hayward \& Krause, 2013).

The status of the elders living with their families was different from those of the old-age home elders. Theme 1 showed that the elders exhibited apprehension in expressing experienced transgressions to 
avoid conflicts with their family members. Thus, this group did not find it easy to express themselves due to the apprehension of defamation, conflicts, or insecurity and fear of losing respect from their family members as they were fully dependent on them. The recognition of the positive role of small rebuke, reprimand and scolding in forgiveness was surfaced in the verbalizations of the majority of the family elders (Theme 2). It may seem that punishment and justice are contradictory but here punishment has been verbalized to enhance forgiveness. This argument also comes from some earlier studies that suggest that punishment may sometimes ease forgiveness (University of Adelaide, 2014; Zaibert, 2010). This may also be due to the Indian cultural values where elder family members exercise small punishments and rebuke to regulate socially and morally expected behaviours in the younger ones that are assumed to be positive and essential (Ahirwar et al., 2019).

Forgiveness of the elders of the family was significantly shaped by their belongingness, good relationships, interdependence and family affiliation (Theme 3). It has been suggested that good relationships and affiliations promote forgiveness (Maio et al., 2008). This may also be due to the fact that older adults show lesser confrontational behaviours than younger adults in the face of an odd situation that may facilitate their forgiveness (Fingerman \& Charles, 2010). Theme 4 reflected that isolation, withdrawal, and guilt played an implicit role in regulating the forgiveness of the elders. This may be due to their perceived disabilities and health issues linked with old age that may have regulated their forgiveness. As isolation and withdrawal may lead one to decreased social support that may refrain them from positive emotional and adaptive outcomes that's why the elders living with their families might have forgiven in the face of some perceived transgressions (Hantman \& Cohen, 2010; Maynard et al., 2016).

Many commonalities were also observed in the perceived transgressions and forgiveness dynamics of the elders of both groups. For both the groups, forgiveness was reported to be linked with psychological, socio-cultural and situational factors. Both the groups recognized that the nature and severity of the transgressions, reparability of harm and degree of the moral violations due to transgressions were important for forgiveness. Moreover, both the groups also accepted the role of relationship with the transgressors, the role of transgressors and acceptance of transgression and age and gender of the transgressors in forgiving. Support for some of the findings of the present study is evident in the existing literature of forgiveness. For instance, family members are far more easily forgiven than outsiders (Hantman \& Cohen, 2010). Likewise, close relationship and role expectations (I am a father or mother and I should forgive my children) positively influence forgiveness (Fincham et al., 2002). Age and gender of the transgressors also emerged as important determinants of forgiveness. Women are generally more readily forgiven compared to men (Hantman \& Cohen, 2010) and so are older adults compared to younger for the same transgression (Fingerman \& Charles, 2010; Miller et al., 2009). The intention behind committing a transgression also surfaced as a significant determinant of forgiveness in the verbalizations of both the groups since unintentional wrongdoings were much easily forgiven. Further, seeking forgiveness by the transgressor was seen to be important for certain transgressions. Other forgiveness studies also indicate that while some people show unconditional forgiveness, others require their transgressor to show repentance, such as making an apology or providing compensation (Krause \& Ellison, 2003; Krause \& Ingersoll-Dayton, 2001).

In short, it may be concluded that there are many similarities and differences in the perceived transgressions and forgiveness of the elders of the old-age homes and the families. The findings showed that severe transgressions, poor social support, negative attributions and age-linked disabilities may be argued to represent major precursors regulating the nature and dynamics of forgiveness of the old-age home elders while relationship, conflict, insecurity, affiliation, dependency and meaningfulness shaped the forgiveness of the elders living in their families. The peculiar role of small punishments, rebukes, moral expectations, social defamation and religious beliefs in regulating the perceived transgressions and consonant forgiveness was indicative of the collectivistic cultural values in action that need further investigation. This study has some marked significance as it has been conducted on samples of Indian society where the joint family system is more prevalent and respect of elders is a cherished value. They had lessons for elders, cautions for youths and fascinating stories for children. They are not a symbol of generation gap but shock absorbers of members across generations. But due to the increasing influence of postmodern lifestyles and material values 
and weakening of the joint family, the elders reported to facing alienated experiences even in their families. The findings of this study should be interpreted in these transitional features of Indian society. Use of small samples and the only use of qualitative method were some limitations of the study.

\section{Implications for Policy and Practice}

These findings may have important implications for understanding forgiveness. Practitioners may devise forgiveness-based interventions keeping in mind the significant similarities and differences in the nature of the perceived transgressions and concomitant challenges of forgiveness of the elders of old-age homes and the families. Policymakers may plan health and well-being policies that provide social support and help in lower grudge to facilitate the achievement forgiveness to enhance the positive life outcomes of the elders. These outcomes may buffer against diseases (as a preventive measure) and increase their longevity. Practitioners should think of using adjunct sources of social support as it may help old-age home elderly to ease their forgiveness. The practitioners may consider plan such interventions that provide social support and melt negative cognitions of the elder people living in old-age homes considering the severe nature of transgressions in their life due to the neglect, loss, helplessness and neglect that may make their forgiveness a bit more difficult to occur.

\section{Data Availability Statement}

The data that support the findings of this study are available from the corresponding author upon reasonable request.

\section{Acknowledgements}

The authors acknowledge the cooperation and support extended by Dr. Yogendra Verma, Miss Ruchi Pandey and Miss Priyanka Parihar, research scholars in the Department of Psychology, School of Humanities \& Social Sciences, Doctor Harisingh Gour Vishwavidyalaya, Sagar, Madhya Pradesh, India, for their input in the planning and conducting of the study as well as active contribution in analysing the data and preparing the manuscript.

\section{Funding Information}

There was no funding for this study.

\section{Conflict of Interest}

None.

\section{Ethical Approval}

The Ethics Committee, Doctor Harisingh Gour Vishwavidyalaya, Sagar, 470003, Madhya Pradesh, India has approved this project.

\section{Descriptions of the Authors' Roles}

Charu Prabhakar, Love Kumar Mishra, Poonam Sharma and Akash Bajpai collected and analyzed the data and contributed in preparing the first draft. Gyanesh Kumar Tiwari, Rakesh Pandey, Meenakshi Shukla and Pramod Kumar Rai conceptualized, designed and supervised the data collection, analysis and writing of initial draft and prepared the final draft of the manuscript.

\section{References}

Ahirwar, G., Tiwari, G. K., \& Rai, P. K. (2019). Exploring the nature, attributes and consequences of forgiveness in children: A qualitative study. Psychological Thought, 12(2), 214-231. 
https://doi.org/10.5964/psyct.v12i2.347

Akhtar, S., Dolan, A., \& Barlow, J. (2017). Understanding the Relationship Between State Forgiveness and Psychological Wellbeing: A Qualitative Study. Journal of Religion and Health, 56 (2), 450-463. https://doi.org/10.1007/s10943-016-0188-9

Barbour, R. S. (2001). Checklists for improving rigour in qualitative research: A case of the tail wagging the dog? BMJ, 322(7294), 1115-1117. https://doi.org/10.1136/bmj.322.7294.1115

Bartholomaeus, J., \& Strelan, P. (2016). Just world beliefs and forgiveness: The mediating role of implicit theories of relationships. Personality and Individual Differences, 96, $106-110$. https://doi.org/10.1016/j.paid.2016.02.081

Bellah, R. N., Madsen, R., Sullivan, W. M., Swidler, A., \& Tipton, S. M. (2008). Habits of the heart: Individualism and commitment in American life (Updated edition with a new introduction, 1 . California paperback edition). University of California Press.

Braun, V., \& Clarke, V. (2006). Using thematic analysis in psychology. Qualitative Research in Psychology, 3(2), 77-101. https://doi.org/10.1191/1478088706qp063oa

Byrne, B. (2016). Qualitative Interviewing. In C. Seale (Ed.), Researching Society and Culture (Fourth Edition, pp. 217-236). Sage Publications Ltd.

Cohen, S., \& Wills, T. A. (1985). Stress, social support, and the buffering hypothesis. Psychological Bulletin, 98(2), 310-357.

Creswell, J. W., Fetters, M. D., \& Ivankova, N. V. (2004). Designing a mixed methods study in primary care. The Annals of Family Medicine, 2(1), 7-12.

Davis, D. E., Ho, M. Y., Griffin, B. J., Bell, C., Hook, J. N., Van Tongeren, D. R., DeBlaere, C., Worthington, E. L., \& Westbrook, C. J. (2015). Forgiving the self and physical and mental health correlates: A metaanalytic review. Journal of Counseling Psychology, 62(2), 329-335. https://doi.org/10.1037/cou0000063

Davis, J. R., \& Gold, G. J. (2011). An examination of emotional empathy, attributions of stability, and the link between perceived remorse and forgiveness. Personality and Individual Differences, 50 (3), $392-397$. https://doi.org/10.1016/j.paid.2010.10.031

Dorn, K., Hook, J. N., Davis, D. E., Van Tongeren, D. R., \& Worthington, E. L. (2014). Behavioral methods of assessing forgiveness. The Journal of Positive Psychology, 9(1), 75-80. https://doi.org/10.1080/17439760.2013.844267

Enright, R. D., Freedman, S., \& Rique, J. (1998). The psychology of interpersonal forgiveness. In $R$. $D$. Enright 8 J. North (Eds.), Exploring forgiveness (pp. 46-62).

Enright, Robert D. (1996). Counseling Within the Forgiveness Triad: On Forgiving, Receiving Forgiveness, and Self-Forgiveness. Counseling and Values, 40(2), 107-126. https://doi.org/10.1002/j.2161007X.1996.tb00844.x

Erikson, E. H., \& Erikson, J. M. (1997). The life cycle completed (Extended version). W.W. Norton.

Fincham, F. D., Paleari, F. G., \& Regalia, C. (2002). Forgiveness in marriage: The role of relationship quality, attributions, and empathy. Personal Relationships, 9(1), 27-37. https://doi.org/10.1111/1475-6811.00002

Fingerman, K. L., \& Charles, S. T. (2010). It Takes Two to Tango: Why Older People Have the Best Relationships. Current Directions in Psychological Science, 19(3), 172-176. https://doi.org/10.1177/0963721410370297

Głaz, S. (2019). The Relationship of Forgiveness and Values with Meaning in Life of Polish Students. Journal of Religion and Health, 58(5), 1886-1907. https://doi.org/10.1007/s10943-019-00860-4 
Griffin, B. J., Cowden, R. G., \& Shawkey, L. A. (2020). Bibliography of narrative reviews and meta-analyses on forgiveness (2004-2018). In E. L., Worthington, Jr., $\mathcal{G}$ N. G., Wade, (Eds.), Handbook of forgiveness (Second Edition, pp. 335-344). Routledge.

Guarnaccia, C. A., \& Zautra, A. J. (1996). The impact of ordinary major and small negative life events on older adults. In P. E. Ruskin \& J. A. Talbott (Eds.), Aging and posttraumatic stress disorder (pp. 139-162). American Psychiatric Press, Inc.

Guest, G., MacQueen, K. M., \& Namey, E. E. (2012). Applied thematic analysis. Sage Publications.

Hall, J. H., \& Fincham, F. D. (2006). Relationship Dissolution Following Infidelity: The Roles of Attributions and Forgiveness. Journal of Social and Clinical Psychology, 25(5), 508-522. https://doi.org/10.1521/jscp.2006.25.5.508

Hantman, S., \& Cohen, O. (2010). Forgiveness in Late Life. Journal of Gerontological Social Work, 53(7), 613-630.

Hayward, R. D., \& Krause, N. (2013). Trajectories of change in dimensions of forgiveness among older adults and their association with religious commitment. Mental Health, Religion \& Culture, 16(6). https://doi.org/10.1080/13674676.2012.712955

Hoffmann, E. A. (2007). Open-Ended Interviews, Power, and Emotional Labor. Journal of Contemporary Ethnography, 36(3), 318-346. https://doi.org/10.1177/0891241606293134

Howitt, D. (2016). Introduction to qualitative research methods in psychology (Third edition). Pearson Education.

Ingersoll-Dayton, B., Torges, C., \& Krause, N. (2010). Unforgiveness, rumination, and depressive symptoms among older adults. Aging \& Mental Health, 14 (4), 439-449. https://doi.org/10.1080/13607860903483136

Knee, C. R., Patrick, H., \& Lonsbary, C. (2003). Implicit Theories of Relationships: Orientations Toward Evaluation and Cultivation. Personality and Social Psychology Review, 7(1), 41-55. https://doi.org/10.1207/S15327957PSPR0701_3

Krause, N., \& Ellison, C. G. (2003). Forgiveness by God, Forgiveness of Others, and Psychological WellBeing in Late Life. Journal for the Scientific Study of Religion, 42(1), 77-93. https://doi.org/10.1111/14685906.00162

Krause, N., \& Ingersoll-Dayton, B. (2001). Religion and the Process of Forgiveness in Late Life. Review of Religious Research, 42(3), 252. https://doi.org/10.2307/3512569

Lawler-Row, K. A. (2010). Forgiveness as a mediator of the religiosity-health relationship. Psychology of Religion and Spirituality, 2(1), 1-16. https://doi.org/10.1037/a0017584

Lee, Y.-R., \& Enright, R. D. (2019). A meta-analysis of the association between forgiveness of others and physical health. Psychology \& Health, 34(5), 626-643. https://doi.org/10.1080/08870446.2018.1554185

Lichtenfeld, S., Maie, M. A., Buechne, V. L., \& Capo, M. F. (2019). Forgiveness and Mental Health Intervention. Frontiers in Psychology, 10.

Maio, G. R., Thomas, G., Fincham, F. D., \& Carnelley, K. B. (2008). Unraveling the role of forgiveness in family relationships. Journal of Personality and Social Psychology, 94(2), 307-319. https://doi.org/10.1037/0022-3514.94.2.307

Maynard, C., Piferi, R. L., \& Jobe, R. L. (2016). Role of Supportive Others in the Forgiveness Process. Counseling and Values, 61(1), 28-43. https://doi.org/10.1002/cvj.12024

McCullough, M. E. (2008). Beyond revenge: The evolution of the forgiveness instinct (1st ed). Jossey-Bass. 
Menezes, S., \& Thomas, T. M. (2018). Status of the Elderly and Emergence of Old Age Homes in India. International Journal of Social Sciences and Management, 5(1), 1-4. https://doi.org/10.3126/ijssm.v5i1.18972

Miller, L. M., Charles, S. T., \& Fingerman, K. L. (2009). Perceptions of Social Transgressions in Adulthood. The Journals of Gerontology Series B: Psychological Sciences and Social Sciences, 64B(5), 551-559. https://doi.org/10.1093/geronb/gbp062

Nelson, E. A., \& Dannefer, D. (1992). Aged Heterogeneity: Fact or Fiction? The Fate of Diversity in Gerontological Research. The Gerontologist, 32(1), 17-23. https://doi.org/10.1093/geront/32.1.17

Nsamenang, S. A., Webb, J. R., Cukrowicz, K. C., \& Hirsch, J. K. (2013). Depressive symptoms and interpersonal needs as mediators of forgiveness and suicidal behavior among rural primary care patients. Journal of Affective Disorders, 149(1-3), 282-290. https://doi.org/10.1016/j.jad.2013.01.042

Pandey, N. M., Tiwari, S. C., \& Singh, I. (2012). Mental health problems among inhabitants of old age homes: A preliminary study. Indian Journal of Psychiatry, 54(2), 144. https://doi.org/10.4103/0019-5545.99533

Pandey, R., Tiwari, G. K., Pandey, R., Mandal, S. P., Mudgal, S., Parihar, P., Rai, P. K., Tiwari, A. S., \& Shukla, M. (2020). The relationship between self-esteem and self-forgiveness: Understanding the mediating role of positive and negative self-compassion [Preprint]. Preprints. https://doi.org/10.22541/au.158981530.01103201

Pandey, R., Tiwari, G. K., Parihar, P., \& Rai, P. K. (2020). The relationship between self-forgiveness and human flourishing: Inferring the underlying psychological mechanisms. Polish Psychological Bulletin, 51(1), 23-36. https://doi.org/10.24425/PPB.2020.132649

Putnam, R. D. (2007). Bowling alone: The collapse and revival of American community. Simon \& Schuster.

Raj, M., \& Wiltermuth, S. S. (2016). Barriers to forgiveness. Social and Personality Psychology Compass, 10(11), 679-690. https://doi.org/10.1111/spc3.12290

Satne, P. (2016). Forgiveness and Moral Development. Philosophia, 44(4), 1029-1055. https://doi.org/10.1007/s11406-016-9727-6

Saunders, B., Sim, J., Kingstone, T., Baker, S., Waterfield, J., Bartlam, B., Burroughs, H., \& Jinks, C. (2018). Saturation in qualitative research: Exploring its conceptualization and operationalization. Quality E Quantity, 52(4), 1893-1907. https://doi.org/10.1007/s11135-017-0574-8

Siassi, S. (2007). Forgiveness, acceptance and the matter of expectation. The International Journal of Psychoanalysis, 88(6), 1423-1440. https://doi.org/10.1516/4W17-3154-1T35-T460

Steiner, M., Allemand, M., \& McCullough, M. E. (2012). Do agreeableness and neuroticism explain age differences in the tendency to forgive others? Personality 83 Social Psychology Bulletin, 38(4), 441-453. https://doi.org/10.1177/0146167211427923

Stone, M. (2002). Forgiveness in the workplace. Industrial and Commercial Training, 34(7), 278-286. https://doi.org/10.1108/00197850210447282

The United Nations. (2019). World Population Prospects-Population Division-United Nations. https://population.un.org/wpp/

Toussaint, L. L., \& Webb, J. R. (2005). Gender Differences in the Relationship Between Empathy and Forgiveness. The Journal of Social Psychology, 145(6), 673-685. https://doi.org/10.3200/SOCP.145.6.673686

Toussaint, L. L., Worthington Jr, E. L., Williams, D. R., \& Webb, J. R. (2020). Forgiveness and Physical Health. In E. L. Worthington Jr. \& N. G. Wade (Ed.), Handbook of Forgiveness (Second Edition, pp. 178-187). Routledge. 
Toussaint, Loren L., Williams, D. R., Musick, M. A., \& Everson, S. A. (2001). Forgiveness and Health: Age Differences in a U.S. Probability Sample. Journal of Adult Development, 8(4), 249-257. https://doi.org/10.1023/A:1011394629736

University of Adelaide. (2014). Punishment plays important role in forgiveness. ScienceDaily. https://www.sciencedaily.com/releases/2014/06/140618100509.htm

Webb, J. R., \& Toussaint, L. L. (2020). Forgiveness, Well-Being, and Mental Health. In E. L., Worthington, Jr., $\&$ N. G., Wade, (Eds.), Handbook of forgiveness (Second Edition, pp. 188-197). Routledge.

World Health Organization. (2019). Suicide Rate By Country 2019. http://worldpopulationreview.com/countries/suicide-rate-by-country/

Worthington, E. L. ,. Jr., O’Connor, L. E., Berry, J. W., Sharp, C., Murray, R., \& Yi, E. (2005). Compassion and forgiveness: Implications for psychotherapy. In P. Gilbert (Ed.), Compassion: Conceptualisations, research and use in psychotherapy (pp. 168-192). Routledge.

Zaibert, L. (2010). Punishment and Forgiveness. In J. Ryberg \& J. A. Corlett (Eds.), Punishment and Ethics (pp. 92-110). Palgrave Macmillan UK. https://doi.org/10.1057/9780230290624_6 